\title{
O DIREITO À MORTE DIGNA SOB A PERSPECTIVA DO DIREITO À AUTONOMIA DO PACIENTE TERMINAL
}

\section{THE RIGHT TO DEATH WITH DIGNITY IN THE PERSPECTIVE OF THE TERMINAL PATIENT'S RIGHT TO AUTONOMY}

\author{
${ }^{1}$ Riva Sobrado De Freitas \\ ${ }^{2}$ Daniela Zilio
}

\section{RESUMO}

O presente artigo tem como objetivo investigar a possibilidade de que o direito à autonomia do paciente terminal possa alicerçar um possível direito à morte digna. Para tanto, foi realizada uma pesquisa bibliográfica exploratório-explicativa, qualitativa, utilizando-se o método dedutivo. A conclusão obtida é a de que, embora não exista pacificidade, é preciso que se atente para um direito de indiscutível relevância, refletido na autonomia decisória, que, ainda que com polêmica, merece ser levado em consideração, inclusive enquanto norte para a concretização do direito de morrer dignamente, até porque, optar pela morte digna não traduz necessariamente abdicar do direito à vida.

Palavras-chave: Autonomia, Morte digna, Vida digna, Bioética

\begin{abstract}
This article has as objective to investigate the possibility that the right to autonomy of terminal patient can base a possible right to death with dignity. Therefore, it was realized a bibliographic exploratory-explanatory research, qualitative, using the deductive method. The obtained conclusion is that, though there isn't peacefulness, it's necessary to attend for a right of unquestionable relevance, reflected in the decisional autonomy, that, even with controversy, deserves to be considered, even as north to the achievement of the right to die with dignity, because, choose the death with dignity doesn't translate necessarily to abdicate from the right to life.
\end{abstract}

Keywords: Autonomy, Death with dignity, Life with dignity, Bioethics

\footnotetext{
1 Pós-doutora em Direito pela Universidade de Coimbra, Portugal. Doutora em Direito pela Pontifícia Universidade Católica - PUC, São Paulo - SP (Brasil). Professora da Universidade do Oeste de Santa Catarina UNOESC, Joaçaba - SC (Brasil). E-mail: rivafreit@gmail.com

${ }^{2}$ Mestranda em Direitos Fundamentais pela Universidade do Oeste de Santa Catarina - UNOESC, Joaçaba - SC (Brasil). E-mail: danielazilio@yahoo.com.br
} 


\section{INTRODUÇÃO}

O estudo em pauta tem como tema central a morte digna e a dúvida acerca da possibilidade de sua realização com base na decisão autônoma do paciente terminal.

Justifica-se o estudo tendo em mente a relevância que ele possui, já que pautas envolvendo a autonomia humana e a possibilidade de que sejam feitas escolhas priorizando um direito (teoricamente) em detrimento de outro, como é o caso da morte digna, são sempre polêmicas. Ademais, o tema referente à possibilidade de realização da afamada morte com dignidade é extremamente atual e, de fato, existem argumentos extremamente importantes, tanto favoráveis quanto contrários à prática, e em todas as áreas do conhecimento que buscam a sua explicação, ou, ao menos, a sua compreensão, o que não é diferente na ciência jurídica.

O problema do estudo pauta-se, então, no seguinte questionamento: o direito à autonomia do paciente terminal pode servir de arrimo para a concretização de um possível direito à morte digna?

Ressalta-se que, não é o foco do presente estudo a análise das diretivas antecipadas de vontade, ou do testamento vital, tampouco objetiva-se vislumbrar a hipótese na qual o paciente terminal não pode manifestar a sua vontade. O que se pretende, assim, é ponderar a hipótese na qual o indivíduo, com base em sua visão de mundo, opta, autonomamente, por morrer da forma que, na sua concepção, é digna, no momento em que a morte é premente.

Objetiva-se, de forma geral, ponderar a possibilidade de que o direito à autonomia decisória do paciente terminal possa alicerçar o seu direito de morrer dignamente. De forma específica, esclarecer o conceito de morte digna, trazer importantes elucidações acerca da autonomia, enquanto direito, e sopesar a possibilidade de que o paciente terminal possa optar pela forma e pelo momento de morrer, dignamente, de acordo com as suas convicções pessoais.

Para tanto, o estudo será sistematizado de modo que, em um primeiro momento será realizada uma análise conceitual acerca da morte digna, em um segundo momento, refletir-seá sobre a autonomia e, por fim, será ponderada a possibilidade de que a autonomia do paciente terminal possa embasar o seu direito de morrer de forma digna.

No que respeita especificamente ao aspecto metodológico, a pesquisa funda-se em procedimentos técnicos, racionais e sistemáticos, com a finalidade de embasamento científico, proporcionando alicerces lógicos à investigação. Trata-se, por fim, de pesquisa de coleta bibliográfica exploratório-explicativa, qualitativa, em que é utilizado o método dedutivo, e em 
que se tem a intenção de explorar e descrever o tema em comento, revelando-se as possíveis soluções para o embate que se apresenta, sem, no entanto, esgotar-se a temática.

\section{A MORTE DIGNA: BREVES PONDERAÇÕES INICIAIS}

De forma inicial, necessário ressaltar-se que, a morte digna a que se pretende referir diz respeito à morte enfrentada de acordo a dignidade pessoal de cada ser. A dignidade pessoal é a condição considerada por cada indivíduo para viver dignamente, independentemente de conceitos genéricos acerca do que seria a afamada dignidade da pessoa humana, até porque, a definição desse conceito não guarda consenso, e, ao que parece, não guardará, pelo menos em um futuro próximo, havendo consenso, isso sim, acerca da dificuldade de sua definição, segundo Meireles (2009).

Não obstante, a conceituação do que seria morrer com dignidade torna-se necessária. A morte é um processo inerente ao próprio processo vital. Deste modo, a morte com dignidade seria aquela ocorrida em momento escolhido pelo próprio titular da vida, buscando como fim a preservação de sua dignidade pessoal. Neste sentido, a morte seria digna caso correspondesse ao que o paciente terminal entenderia por ser digno para sua própria vida.

Aliás, muito pouco se sabe acerca da morte. A despeito disso, tem-se a única certeza de que ela é inevitável, e é esse justamente o motivo pelo qual se busca o critério de morte digna e humanizada. A saber, o acontecimento da morte já parece ser algo terrificante, justamente pelo medo ligado à ideia de extinção, de deixar de viver, e a tentativa de torná-la um momento um tanto quanto mais confortável, evitando-se o sofrimento exacerbado, é, por assim dizer, o argumento de busca pela dignificação deste momento tão cheio de medos e inseguranças por sua própria natureza. Falar em morte digna, assim, é falar de respeito à dignidade da vida do enfermo terminal.

Relata Giostri (2006) que, todos têm direito a viver com dignidade. E do mesmo modo que as pessoas têm o direito de ver respeitada a sua dignidade durante toda a vida, merecem também tê-la respeitada no momento em que é chegada a hora crucial da decisão entre a morte digna e menos dolorosa, e aquela prolongada, com uma enorme carga de dor e sofrimento.

Dworkin (2003) respalda o entendimento de defesa pela morte digna reiterando que todos os dias, ao redor do mundo, pessoas racionais pedem que lhes seja permitido morrer, 
por vezes implorando que outras pessoas os suprimam a vida. Algumas delas já se encontram em processo de morte, em estado de insuportável sofrimento, e outras, preferem morrer por não quererem mais permanecer vivas da única maneira que lhes resta. Finalmente, ocorrem casos em que os parentes pedem permissão para pôr fim à vida de algum membro da família, pois o paciente em questão já se encontra em estágio vegetativo irreversível.

Para Fabriz (2003), quem defende a morte digna expõe que a recusa a fazer determinado procedimento terapêutico não significa recusar-se a viver. $\mathrm{O}$ indivíduo, com base em sua visão de mundo, faz sua escolha, arcando com os possíveis e prováveis riscos. Cabe ao terapeuta adotar procedimentos que possibilitem o bem-estar cabível ao caso. Caso o paciente venha a falecer, não há que se questionar, pois a morte faz parte do próprio processo de vida. O paciente, autônomo, assim decidiu, arcando com a possibilidade da morte, e assim entendeu alcançar uma morte digna, eis que enquadrada em seu conceito de vida digna. Morrer dignamente é aceitar a morte como um fato inexorável da própria vida.

Aliás, são válidos os ensinamentos de Pessini (2004) no sentido de que morrer com dignidade é um termo complexo e inclui um marco assistencial e um ambiente afetivo. Dessa forma, a morte digna precisa ocorrer em um lugar específico, cercado das pessoas com as quais se possui um vínculo afetivo e reconciliado consigo mesmo.

Nesta senda, a preservação da vida apenas pelo privilégio de sua dimensão biológica, negligenciando-se a qualidade a ser proporcionada ao indivíduo, segundo Sá (2001), não pode mais ser considerada nos dias hodiernos, de acordo com esse entendimento. A vida prolongada é justificável caso traga algum melhoramento e desde que não fira a dignidade do viver e do morrer, caso contrário, a morte digna deve ser aceita, por respeitar todas as demais dimensões constitutivas de um indivíduo, e não apenas a questão biológica.

A morte deve ser enfrentada, então, como sendo parte essencial da vida e algo que, inclusive, fornece-lhe sentido, não permitindo que ela caia em uma continuidade inócua e insípida, conforme Cabette (2009).

Ainda, para Möller (2007), como categoria jurídica de valor aberto que é, a dignidade pessoal (e a questão da morte digna), deve ser enfrentada caso a caso, de maneira que cabe ao paciente terminal a definição do conteúdo do que para si seria uma morte digna, para o fim de colocá-la em prática.

Como ressalta Ribeiro (2006), a morte digna também é um direito humano, compreendendo-se esta como a morte sem dor ou angústia, em consonância com a vontade do titular do direito de viver e de morrer. Para o autor, é paradoxal a postura da sociedade, muitas 
vezes emanada de uma religiosidade que a religião desconhece, que compreende seja o sofrimento do animal poupado, mas que não permite, com o mesmo argumento e nas mesmas condições, afastar o sofrimento de pessoas capazes e autônomas.

Denota-se que o conceito de morte digna está atrelado à questão altruísta e humanitária de encarar o processo de morte, coadunando-se na maneira de se preservar o paciente terminal, proporcionando-lhe uma morte tranquila e humanizada, quando da não possibilidade de manutenção de sua vida, com dignidade.

Ressalta-se, assim, que não se pretende relatar de forma específica a mera conceituação da eutanásia, ou das práticas correlatas - como a ortotanásia, a mistanásia e o suicídio assistido - mas explicitar o que poderia ser o morrer dignamente, na visão do próprio paciente terminal, de acordo com os seus valores pessoais, entre eles, a autonomia para decidir o melhor momento e a melhor forma de morrer, quando de qualquer modo a morte é iminente e inevitável. É em relação à autonomia, inclusive, que se atenta o estudo a partir de agora.

\section{A AUTONOMIA: IMPORTANTES ELUCIDAÇÕES}

Etimologicamente, a expressão autonomia, presente nos dicionários a partir de 1836, resulta da conjunção de duas palavras gregas, quais sejam: autós e nomói, de acordo com Rodrigues Junior (2004). Da primeira vem a ideia de si mesmo, representando uma qualidade ou condição inerente e peculiar a um ser. A segunda corresponderia à norma ou regra. A junção de ambas gerou autonomia, que ingressou no vernáculo muito provavelmente por influência da palavra francesa autonomie.

De acordo com Beauchamp e Childress (2013), o vocábulo autonomia foi utilizado em primeiro plano para a referência quanto à autogestão ou autogoverno das cidades-estados independentes gregas. Desde então, foi estendido aos indivíduos e ganhou diferentes sentidos, como os direitos de liberdade e privacidade, escolha individual, liberdade da vontade, motor do próprio comportamento e pertencer a si mesmo. Sendo assim, a autonomia não pode ser considerada enquanto conceito unívoco, nem na língua comum, nem na atual filosofia, de modo que é preciso que se o refine com base em objetivos específicos.

Pois bem. A ideia de autonomia e de respeito pelas escolhas autônomas dos indivíduos apresenta-se de forma bastante intensa, mas ainda cheia de lacunas, no que se relaciona ao direito. A filosofia, por sua vez, se imiscui no tema há muito. Filósofos do porte 
de Immanuel Kant e John Stuart Mill buscaram interpretar a autonomia, e influenciam as atuais compreensões do tema.

Segundo o entendimento de Kant (2003), a liberdade, ou mais profundamente, a autonomia, e a própria dignidade humana, sempre foram figuras próximas, sendo aquela o fundamento desta e de toda a natureza racional. Tanto é assim, que o autor explicitou que a moralidade existe na relação das ações com a autonomia da vontade, com a aptidão do ser racional de legislar e submeter-se à lei legislada, sendo tratado como fim, e nunca simplesmente como meio.

De seu turno, John Stuart Mill ${ }^{1}$ compreendeu a liberdade de maneira diversa. De acordo com Möller (2007), a liberdade foi concebida por ele como a liberdade individual de escolha, onde exista respeito à diversidade das opiniões, sentimentos e modos de vida. Ainda, é defendida por Mill a proteção da esfera de liberdade da pessoa que diz respeito a ela própria, sem prejuízo às outras pessoas. $\mathrm{O}$ autor preocupou-se, assim, com a defesa da liberdade de escolha do ser humano, no que se relaciona à esfera mais particular de sua vida, da mesma maneira que se preocupou com a proteção da diversidade de opiniões, sentimentos e formas de compreensão da vida.

Inclusive, o autor defende que a única liberdade que faz jus a esse nome é a liberdade de prosseguir o próprio bem, da maneira própria, obviamente sem privar os outros de sua própria liberdade, nem obstruir seus esforços para alcançá-la. Argumenta Mill (2010) que cada qual é guardião de sua saúde, seja ela física, mental ou mesmo espiritual, e quem acaba vencendo é a humanidade, ao deixar que cada pessoa viva como lhe pareça ser melhor, muito mais do que essa mesma humanidade venceria, caso coagisse os indivíduos a viverem conforme parecesse ser melhor para as demais pessoas.

Também Benjamin Constant, a seu modo, já apontava a autonomia explicitando a liberdade moderna, coadunada no direito de expressar opiniões, de discutir interesses ${ }^{2}$.

\footnotetext{
1 As preocupações do filósofo se mostram extremamente atuais, ainda mais no que se relaciona ao problema proposto no presente estudo, justamente pela preocupação demonstrada por ele quanto à liberdade de escolha do indivíduo e as diferentes concepções de vida.

${ }^{2}$ A liberdade moderna, como mencionado, é relatada por Benjamin Constant como o direito de expressar opiniões, de discutir interesses. A liberdade dos antigos consistiu em exercer coletivamente e diretamente várias partes da soberania inteira, deliberar em praça pública, votar as leis, dentre outras coisas. Porém, compatível a esta liberdade seria a submissão completa do indivíduo à autoridade do todo. Todas as ações privadas estiveram sujeitas à vigilância. A liberdade individual era mitigada, pois nem mesmo no que se refere à religião era respeitada. Até nas relações domésticas havia intervenção. As leis regulamentavam os costumes e tudo era dependente deles. Assim, nada havia que a lei não regulamentasse. Deste modo, o indivíduo soberano nas questões públicas, foi escravo nos assuntos privados. Veja-se, como cidadão, o indivíduo decidia sobre a paz e sobre a guerra, por exemplo, e como particular, permanecia limitado, reprimido.
} 
A autonomia que se pretende analisar aqui é convergente à ideia exposta por John Stuart Mill, aquela concernente ao direito de cada ser humano de discernir o que cabe para si, de acordo com suas vivências pessoais, pressupondo-se que exista, de fato, uma variedade de concepções do que seja bom para cada indivíduo.

Autonomia essa que se coaduna com o que Beauchamp e Childress (2013) esclarecem como a autonomia pessoal, enquanto distinta do autogoverno político: o governo pessoal do "eu" que é livre, tanto por parte de interferências controladoras de outras pessoas, quanto de limitações pessoais que obstam a escolha expressiva da intenção, como a compreensão inadequada. O ser humano autônomo, assim, age de forma livre, de acordo com um plano escolhido por ele mesmo, assim como um governo independente administra seu território e define suas políticas.

Destarte, conforme Barroso e Martel (2010) a autonomia a que se alude expressa a dignidade, e decorre da liberdade e da igualdade das pessoas. Assim, a autodeterminação individual e o direito ao respeito e à consideração, fazem parte do conteúdo da dignidade. Todos podem eleger seus projetos existenciais e não devem, por isso, sofrer discriminações, tampouco em função de sua identidade e de suas escolhas.

Deste modo, de acordo com os autores, a dignidade enquanto autonomia inclui o poder de autodeterminação e o direito de discernir acerca dos rumos da própria vida, e de desenvolver de forma livre a própria personalidade. Para além da ideia de autonomia, existe alguém moral, capaz de se autodeterminar, fazer planos e colocá-los em prática.

Nesta senda, não caberia ao Estado, à coletividade ou a qualquer que fosse a entidade o estabelecimento do caminho que cada pessoa deve seguir, os valores que deve crer ou as atitudes que deve ter, cabendo a cada ser humano discernir os rumos que suas vidas devem tomar, de acordo com as suas opções subjetivas, conforme Pires e Reis (2010).

Ainda, na visão de Durand (2012), no que se relaciona à autonomia propriamente no que concerne à ética, relaciona-se que ela é, em primeiro lugar, a capacidade de discernimento no sentido do bem e do justo. O sentido da autonomia é a liberdade de decidir de modo responsável, a responsabilidade de refletir sobre o que é bom e de discernir no sentido do bem, de refletir sobre as exigências objetivas do respeito e da promoção da dignidade humana em si próprio e em cada ser, de escolher uma ação que segue o sentido do respeito a cada ser humano e a todo o ser humano.

Ademias, em termos constitucionais, relata ainda Möller (2007) que, o princípio constitucional da liberdade carrega implicitamente consigo a ideia de respeito à autonomia do 
ser humano, e de respeito à aptidão para a autodeterminação no que se refere exclusivamente ao próprio indivíduo, na sua esfera de liberdade mais íntima, desde que não lese a esfera de liberdade dos demais.

Denota-se, de tal modo, que embora o termo não seja de conotação uníssona, o exercício da autonomia é um direito de importância indiscutível. Outrossim, justamente pela relevância assumida por ela em situações existenciais, a autonomia foi galgada a princípio da bioética. É o que se explicita adiante.

\subsection{A Autonomia como Princípio da Bioética}

A autonomia, enquanto princípio da bioética, consagra-se a partir da elaboração do Relatório Belmont (Belmont Report), estruturado no Centro de Convenções Belmont, no Estado de Maryland, Estados Unidos da América, no ano de 1978, pela Comissão Nacional para a Proteção dos Seres Humanos da Pesquisa Biomédica e Comportamental (National Commission for the Protection of Human Subjects of Biomedical and Behavioral Research) comissão essa instituída pelo governo americano em 1974, de acordo com Silva (2012).

Tal relatório foi pensado, em princípio, para a proteção em face das discrepâncias cometidas nos experimentos científicos envolvendo seres humanos, ou seja, a referida Comissão foi constituída para identificar princípios capazes de alicerçar a experimentação que envolvesse seres humanos, de acordo com Pessini e Barchifontaine (2000).

Porém, conforme explicita Silva (2012), o relatório Belmont elevou-se à declaração principialista da reflexão bioética, levando influencias para muito além dos experimentos aludidos, já que pautado na aceitação de três princípios éticos. Levando-se em consideração que não existe ação humana autônoma se não houver prévio consentimento livre e informado, identificam-se três princípios no relatório: o respeito pela pessoa (autonomia), que engloba a convicção de que todos os indivíduos carecem ser tratados com autonomia e a convicção de que as pessoas que tenham autonomia diminuída ou estejam em desenvolvimento necessitam ser protegidas (vulnerabilidade); a beneficência (não causar danos, maximizar os benefícios e minimizar os possíveis riscos); e justiça (neutralidade na questão da distribuição dos riscos e benefícios) ${ }^{3}$.

\footnotetext{
${ }^{3}$ À guisa de esclarecimento, necessário que se comente que o quarto princípio, coadunado na não maleficência, foi proposto na obra "Princípios de Ética Biomédica" (Principles of biomedical ethics), publicada no ano de 1979, por Tom L. Beauchamp e James F. Childress. A bioética principialista teve como precursores os autores mencionados, com a publicação da obra referida. Saliente-se, inclusive, que Tom L. Beauchamp fez parte da comissão que elaborou o Relatório Belmont.
} 
Assim, o princípio da autonomia, uma vez consagrado, formalizou-se como um marco histórico nas transformações da ética médica paternalista, a favor do consentimento livre e esclarecido. Ribeiro (2006) argumenta, inclusive, o hodierno empoderamento do paciente sobre sua saúde, o empowerment health. O paciente conquistou o poder de tomar decisões sobre sua saúde e sobre sua própria vida, passando de sujeito passivo a titular do direito. Por sua vez, o profissional de saúde passa de sujeito ativo a titular de uma obrigação. Antes soberano na tomada de decisões clínicas, o profissional da saúde migra ao papel de conselheiro, dialogando francamente com o paciente, este sim titular do direito de tomá-las, a partir do esclarecimento que lhe é devido.

Segundo Santoro (2010), então, com o princípio da autonomia merece ser respeitada a capacidade de decisão do ser humano. Essa autonomia está diretamente correlacionada à liberdade individual, alicerçada na vontade, que não pode ser imposta, nem mesmo pelo médico. De acordo com o que elucida o autor, o direito à escolha do tratamento médico tem respaldo constitucional nos artigos $5^{\circ}$, caput, e incisos IV, VI, VIII e X, e 19, inciso I, da Constituição Federal.

Inclusive, o próprio Código de Ética Médica, em respeito à autonomia do paciente, prevê que é direito do médico prescrever o tratamento adequado ao paciente (capítulo II, inciso II), sem, contudo, limitar o respeito à vontade daquele de decidir sobre seu bem-estar (capítulo IV, artigo 24) e sem desrespeitar o direito à livre decisão sobre a execução de práticas diagnósticas ou terapêuticas (capítulo V, artigo 31), excetuando-se casos de iminente perigo de vida. Assim, de acordo com Santoro (2010), visando à obtenção da liberdade do enfermo em decidir, deve haver a informação por parte do médico, quanto ao diagnóstico, o prognóstico, os riscos e objetivos do tratamento, salvo quando a informação direta possa lhe causar dano, hipótese na qual quem deve ser informado é o seu responsável legal (artigo 34, capítulo V).

Por óbvio que em circunstâncias ditas por normais e não de terminalidade da vida, onde a vida do paciente pode ser salva, o profissional da medicina poderá tomar atitudes que vão de encontro à vontade do paciente, conforme o Código de Ética Médica expressa. Como exemplo, cita-se o artigo 26, do capítulo IV, que esclarece que a greve de fome deve ser respeitada até o limite de perigo iminente de morte, quando o médico poderá tratar o paciente. Da mesma forma, cita-se a recusa à transfusão de sangue, onde o médico procurará 
tratamentos alternativos, a não ser em perigo iminente de morte, hipótese na qual ela será feita independentemente de consentimento ${ }^{4}$, segundo relaciona Santoro (2010).

Porém, em casos de estágio avançado de doença terminal, onde a morte é fato inexorável, a recusa ao tratamento precisa ser respeitada.

Também a legislação pátria já contempla o respeito à autonomia do paciente, conforme Ribeiro (2006). Porém, segundo o autor, o Código Civil brasileiro, com suas três décadas de gestação, utiliza termos paternalistas. O artigo 13 aduz que "salvo por exigência médica, é defeso o ato de disposição do próprio corpo, quando importar diminuição permanente da integridade física, ou contrariar os bons costumes". Conforme explicita, não existe mais exigência médica. A autonomia deu lugar à indicação, à recomendação, à prescrição, deixando de lado a exigência, a ordem.

Tal dispositivo legal deve ser vislumbrado à luz da Constituição Federal, tendo em vista a própria constitucionalização do direito civil. Sendo dessa forma, qualquer interpretação que se faça sobre o tema, deve ser levando em consideração a cláusula geral de proteção da dignidade humana, assim como a autonomia nas situações existenciais.

No artigo 15 do mesmo Códex, semelhante situação: "ninguém pode ser constrangido a submeter-se com risco de vida, a tratamento médico ou a intervenção cirúrgica", levando-se a crer que existe obrigação de aceitar tratamento ou cirurgia sem risco de vida, o que seria, na atualidade, um contrassenso ético e jurídico. Para Ribeiro (2006) a contemporânea leitura do artigo em voga "conforme a Constituição" demanda ser, de acordo com o autor: "ninguém, nem com risco de vida, será constrangido a tratamento ou a intervenção cirúrgica", respeitando-se a sua autonomia.

Pois bem. Resta claro, com o estabelecido, que a autonomia do paciente, coadunada na capacidade de decisão, é consagrada, também no que se relaciona à bioética, por ter sido eleita como um dos seus princípios, e deve ser respeitada, inclusive, pela classe médica. Aludida autonomia em casos de opção pela morte com dignidade, de frente à morte vindoura - estágios de terminalidade da vida humana - será examinada nas ulteriores linhas.

\footnotetext{
${ }^{4}$ Sobre o assunto, o Conselho Federal de Medicina aprovou a Resolução 1.021/80.
} 


\section{A AUTONOMIA DO PACIENTE TERMINAL COMO NORTE NA CONCRETIZAÇÃO DA MORTE DIGNA}

Devidamente explicitada, ao menos sinteticamente, a morte digna, e abordado o tema concernente à autonomia humana, neste momento, faz-se premente a necessidade de análise dos temas conjuntamente, de modo a questionar-se se, o paciente terminal, dotado de autonomia, pode optar pelo melhor momento e a melhor forma de morrer, dignamente.

Nos dias atuais, as tecnologias utilizadas no tratamento médico de pacientes em estágio terminal por vezes acarretam maior dor e sofrimento do que o próprio mal que o acomete, prolongando o processo de morte, muitas das vezes, para além do que deseja o próprio adoentado. Nesse momento é que surge a indagação sobre a possibilidade da existência do direito de morrer de forma digna e humanizada, ocorrida a morte pelo respeito à decisão autônoma do titular da vida.

O que é colocado em pauta é a possibilidade de que se antecipe o momento da morte, pela vontade do paciente terminal, para que ela ocorra respeitando os seus valores e de acordo com a concepção de morte com dignidade defendida por ele próprio.

Sendo assim, com frequência é levantada a questão de que o direito à vida não pode ser encarado como um dever, uma obrigação de viver, mas um direito a ser exercido em consonância com outros valores, como a dignidade e a autonomia. É o que defende Ribeiro (2006) ao relatar que o direito de viver, por ser direito potestativo, é renunciável somente pelo seu titular. Caso não fosse renunciável, não seria direito, mas "dever" de viver. E enquanto "dever" de viver, geraria consequências jurídicas diferentes das que hoje são conhecidas, a começar pela punição da tentativa de suicídio, proibição dos esportes radicais e mesmo atividades de risco, e desencadearia a mecanização da vida para além da vida, causando tratamentos desumanos e degradantes ao doente.

No que se relaciona à morte, Dworkin (2003) expressa seu entendimento no sentido de que a forma como a pessoa morre é importante, de modo que precisa ser respeitado o direito do indivíduo de que a sua morte seja reflexo da maneira como ele a viveu, ou seja, que essa hora crucial seja coerente com as convicções e os valores adotados pela pessoa em vida, de tal forma que as pessoas terminem as suas vidas de acordo com os parâmetros que sempre as nortearam. Note-se que o autor prima prioritariamente pelo respeito à decisão autônoma do indivíduo. 
Na mesma linha de entendimento, Möller (2007) destaca que defende um direito à morte com dignidade e autonomia por compreender que ambos os princípios estão entrelaçados na questão do final da vida e da determinação dos nortes de tratamentos de pacientes terminais, possibilitando a conformação da noção de um direito do paciente a morrer conforme seus valores e suas crenças. Defende que cada ser humano autônomo é capaz de discernir o que significa para si morrer dignamente. A autora parte do pressuposto de que a dignidade é um valor de conteúdo aberto, que pode se modificar de acordo com a evolução histórica e com a visão dos indivíduos e das comunidades culturais particulares.

Da mesma forma, relata que, a noção de morte digna e com autonomia tende a respeitar o pluralismo moral, a diversidade de crenças e de visões sobre a vida boa ${ }^{5}$, já que reconhece que existem diferentes entendimentos sobre o que é morrer dignamente. A forma como cada qual reage frente às situações (inclusive em relação à morte) é influenciada ou determinada, em síntese, tendo-se em mente a comunidade ou ambiente cultural aos quais se pertence, ou em função dos valores individuais de cada qual, não necessariamente identificados ou identificáveis com uma visão moral coletiva.

Prega-se, assim, a tolerância quanto aos diferentes modos de vida, tolerância essa a ser exercida inclusive pelos profissionais da medicina, familiares, Estado e indivíduos de uma forma geral, no enfrentamento da morte digna - digna na concepção autônoma do próprio titular da vida ${ }^{6}$.

Sendo dessa forma, concretamente, na bioética, no que toca ao paciente, ao sujeito, ao cidadão, respeitar a autonomia, de acordo com Durand (2012), não é apenas recorrer à sua autodeterminação, mas sim ajudar essa pessoa a ir ao limite de si mesma, de maneira a ajudála a descobrir e a escolher o que está de acordo com o sentido do respeito à dignidade humana. Outrossim, isso não significa exercer pressão sobre o paciente, não impondo nada, mas ajudando-o.

\footnotetext{
5 Acerca das noções de vida boa e da dificuldade de conceituação do que seria a vida boa, bem como a inexistência de consensos aceitáveis universalmente em relação ao tema, Jürgen Habermas tem impressionantes escritos. Recomenda-se a leitura da obra “O Futuro da Natureza Humana: A caminho de uma eugenia liberal?".

${ }^{6}$ Note-se que a defesa da morte digna tem como pressuposto o respeito à decisão autônoma do paciente terminal, inclusive no que se relaciona ao seu entendimento de dignidade, à sua dignidade pessoal. Enquanto para muitos é digno "lutar até o fim", quando o último sopro de vida (sobrevida) ainda existe, para outros, ter a morte antecipada, humanizando este momento, é garantir a dignidade da vida como um todo.
} 
Impõe-se, assim, o respeito à vontade do doente terminal, ainda mais em sociedades pluralistas, onde existe uma infinidade de concepções culturais e filosóficas que, impreterivelmente, geram diferentes concepções acerca da morte e suas conjecturas.

Sztajn (2002) entende, nessa linha de raciocínio, que, o Estado tem interesse em proteger a vida de uma forma geral. Em uma vida em particular, no entanto, caso o sofrimento a torne impossível suportar, levando à degradação física e ao eventual comprometimento da saúde mental, é necessário que prevaleça o interesse individual, de modo a garantir a dignidade pessoal do sujeito. Assim, o direito à vida não pode preponderar a qualquer custo, e, em situações extremas de terminalidade da vida, o direito de morrer com dignidade salvaguarda os direitos do indivíduo que assim o deseja.

Sá (2001) corrobora o entendimento favorável à morte digna tendo como parâmetro a decisão autônoma do adoentado. Comenta que o prolongamento do processo de morte teria justificativa no eventual benefício trazido ao paciente terminal. Na hipótese de não existirem benefícios, a morte digna, desde que autonomamente escolhida por ele, sem pressão ou coação, deve ser aceita, por respeitar, conforme mencionado alhures, todas as dimensões que constituem o indivíduo, e não a mera constituição biológica.

É preciso que se destaque, outrossim, que a morte digna, a ser realizada pelo respeito à autonomia do titular da vida, tem espaço quando a inexorável morte está próxima, e o sofrimento do prolongamento do processo de morte torna-se insustentável na concepção do próprio adoentado.

Inclusive, ressalta-se a autonomia decisória do paciente enquanto única forma para a realização da morte digna. Se assim não fosse, estar-se-ia de frente a uma morte roubada, que em nenhum momento é justificada, de acordo com o entendimento manifestado por Freitas e Baez (2014).

Por fim, salienta-se que a autonomia decisória demanda capacidade de expressão. Há casos, todavia, em que o paciente encontra-se impossibilitado para decidir por si só, onde se pode recorrer a testamentos vitais ou diretivas antecipadas de vontade, enquanto instrumentos de manifestação da vontade para o futuro, conforme Freitas e Baez (2014). Da mesma forma, levanta-se a dúvida acerca da possibilidade de que crianças que se encontram em situações semelhantes (estágio de terminalidade da vida humana) possam manifestar de forma válida o seu direito de permanecerem ou não vivas - ou mesmo seus pais ou tutores. Ressalte-se que os casos mencionados não são objeto do presente estudo, pois se priorizou aqui a análise da situação em que o paciente encontra-se em uma situação de morte iminente e inexorável, e 
que, lúcida e autonomamente, opta por morrer dignamente a continuar sobrevivendo da única maneira que lhe é possível. Contudo, merecem atenção da ciência jurídica os casos mencionados, tendo em vista a peculiaridade da situação.

\section{CONCLUSÃO: CONSIDERAÇÕES FINAIS}

Pautas envolvendo a autonomia humana e a possibilidade de decisão frente a peculiares situações são sempre polêmicas. Em relação ao tema em que é embasado o artigo em voga não poderia ser diferente. O possível direito à morte digna desperta entendimentos completamente divergentes, tanto em relação à esfera jurídica quanto às demais áreas que buscam a sua compreensão. Do mesmo modo, embora questionado desde os mais remotos tempos, o assunto permanece em relevo, sendo o questionamento apresentado atual e deveras importante.

A morte digna, a que se pretendeu ponderar nas precedentes linhas, diz respeito à morte ocorrida de acordo com os valores estabelecidos pelo próprio paciente terminal. Não se buscou realizar um estudo específico e direcionado acerca da eutanásia ativa praticada por terceiro (que consiste em uma ação concreta capaz de causar a morte ou acelerá-la), mas vislumbrar o momento em que o próprio adoentado decide pela morte (que de qualquer forma é premente), porque de acordo com os valores constituídos para sua vida.

Nesse momento é que entra em pauta a autonomia humana, no presente estudo estabelecida enquanto liberdade de escolha em relação ao campo mais íntimo da vida do indivíduo, de modo que sejam resguardadas as diferentes concepções de vida e do que seja a vida boa e a consequente morte boa.

Saliente-se, conforme referido alhures, que o tema desperta discussões sempre acaloradas entre os defensores de um pretenso direito absoluto à vida, e aqueles que entendem ser correto o direito de opção pela morte digna e humanizada. Porém, o que se pretendeu aqui explicitar é que quem decide, autonomamente, por morrer dignamente, quando de qualquer modo a morte é evento iminente, não está renunciando ao seu direito de viver, mas vivendo o seu último ato de vida (a morte), da maneira como crê ser a melhor. Logo, não se almejou aqui contrapor o direito à vida e o direito à autonomia, porque se concebe que não há renúncia do direito de viver, ao optar-se por morrer dignamente.

Até porque, não é implícita à proteção da vida a existência de um dever de viver, de continuar vivendo em condições extremas de sofrimento e frente à implacável proximidade da 
morte.

Então, seguindo essa corrente de pensamento, tem-se que o paciente terminal, dotado de autonomia, tem o direito de discernir pelo melhor momento e a melhor forma de morrer, e, se essa decisão não confronta o seu direito de viver, consequentemente, deve ser respeitada, de tal forma que a autonomia, sob este viés, pode embasar o direito a uma morte digna, tranquila e humanizada.

\section{REFERÊNCIAS}

BARROSO, Luís Roberto; MARTEL, Letícia de Campos Velho. A morte como ela é: dignidade e autonomia individual no final da vida. Revista Panóptica: Direito, sociedade e cultura, v. 5, n. 2, p. 69-104, 2010. Disponível em: <http://www.panoptica.org/seer/index.php/op/article/view/271/293>. Acesso em: 3 maio 2015.

BEAUCHAMP, Tom L.; CHILDRESS, James F. Princípios de ética biomédica. Tradução Luciana Pudenzi. 3. ed. São Paulo: Loyola, 2013. 574 p. Tradução de: Principles of Biomedical Ethics.

BRASIL. Código Civil. Lei n. 10.406, de 10 de janeiro de 2002. Disponível em: <http://www.planalto.gov.br/ccivil_03/leis/2002/L10406.htm>. Acesso em: 11 nov. 2015.

BRASIL. Constituição: República Federativa do Brasil de 1988. Brasília, DF: Senado Federal, 1988.

CABETTE, Eduardo Luiz Santos. Eutanásia e Ortotanásia: comentários à Resolução 1.805/06 CFM Aspectos Éticos e Jurídicos. Curitiba: Juruá, 2009. 124 p.

CONSElHO FEDERAL DE MEDICINA. Código de Ética Médica: Aprovado pela Resolução 1.931, de 17 de setembro de 2009. Diário Oficial da União, Brasília, DF, 24 set. 2009. Seção I, p. 90. Brasília: CFM, 2010. Disponível em: $<$ http://portal.cfm.org.br/index.php?option=com_content\&view=category\&id=9\&Itemid=122 >. Acesso em: 20 fev. 2016.

CONSTANT, Benjamin. Da Liberdade dos antigos Comparada à dos Modernos. Disponível em: < http://www.fafich.ufmg.br/ luarnaut/Constant_liberdade.pdf>. Acesso em: 25 out. 2015.

DURAND, Guy. Introdução geral à Bioética: história, conceitos e instrumentos. Tradução Nicolás Nyimi Campanário. 4. ed. São Paulo: Edições Loyola, 2012. 431 p. Tradução de: Introduction générale à la bioéthique

DWORKIN, Ronald. Domínio da Vida: aborto, eutanásia e direitos individuais. Tradução Jefferson Luiz Camargo. 1. ed. São Paulo: Martins Fontes, 2003. 362 p. Tradução de: Life's Dominion. 
FABRIZ, Daury Cesar. Bioética e direitos fundamentais. Belo Horizonte: Mandamentos, 2003. 398 p.

FREITAS, Riva Sobrado de; BAEZ, Narciso Leandro Xavier. Privacidade e o direito de morrer com dignidade. Revista de Ciências Jurídicas Pensar, Fortaleza, v. 19, n. 1, p. 249269, 2014. Disponível em: < http://ojs.unifor.br/index.php/rpen/article/view/2419/pdf>. Acesso em: 19 ago. 2015.

GIOSTRI, Hildegard Taggesell. A morte, o morrer, a doação de órgãos e a dignidade da pessoa humana. In: CORRÊA, Elídia Aparecida de Andrade; GIACOIA, Gilberto; CONRADO, Marcelo (Coord.). Biodireito e Dignidade da Pessoa Humana: diálogo entre a Ciência e o Direito. Curitiba: Juruá, 2006. p. 155-170.

KANT, Immanuel. Fundamentação da metafísica dos costumes e outros escritos. Tradução Leopoldo Holzbach. São Paulo: Martin Claret, 2003. 139 p.

MEIRELES, Rose Melo Venceslau. Autonomia Privada e Dignidade Humana. Rio de Janeiro: Renovar, 2009. 336 p.

MILL, John Stuart. Sobre a liberdade. Tradução Ari R. Tank Brito. São Paulo: Hedra, 2010. $208 \mathrm{p}$.

MÖLLER, Letícia Ludwig. Direito à Morte com Dignidade e Autonomia. 1. ed. Curitiba: Juruá, 2007. 186 p.

PESSINI, Léo. Eutanásia: por que abreviar a vida? São Paulo: Edições Loyola, 2004.

; BARCHIFONTAINE, Christian de Paul de. Problemas atuais de bioética. São Paulo: Loyola, 2000.

PIRES, Eduardo; REIS, Jorge Renato dos. Autonomia da Vontade: um princípio fundamental do direito privado como base para a instauração e funcionamento da arbitragem. In: XIX ENCONTRO NACIONAL DO CONPEDI, 2010, Fortaleza. Anais eletrônicos... [S.1.: s.n.], 2010. Disponível em: $\langle$ http://www.conpedi.org.br/manaus/arquivos/anais/fortaleza/3874.pdf $>$. Acesso em: 2 maio 2015.

RIBEIRO, Diaulas Costa. Autonomia: Viver a própria vida e morrer a própria morte. Cadernos de Saúde Pública, Rio de Janeiro, v. 22, n. 8, p. 1749-1754, 2006.

RODRIGUES JUNIOR, Otávio Luiz. Autonomia da vontade, autonomia privada e autodeterminação: notas sobre a evolução de um conceito na modernidade e na pósmodernidade. Revista de Informação Legislativa, Brasília, v. 41, n. 163, p. 113-130, 2004. Disponível em:< http://www2.senado.leg.br/bdsf/item/id/982 >. Acesso em: 21 set. 2015.

SÁ, Maria de Fátima Freire de. Direito de Morrer: eutanásia, suicídio assistido. Belo Horizonte: Del Rey, 2001. 195 p. 
SANTORO, Luciano de Freitas. Morte Digna: o direito do paciente terminal. Curitiba: Juruá, 2010. $188 \mathrm{p}$.

SILVA, Reinaldo Pereira e. Biodireito: o novo direito da vida. In: WOLKMER, Antonio Carlos; LEITE, José Rubens Morato (Org.). Os "novos" direitos no Brasil: natureza e perspectivas - uma visão básica das novas conflituosidades jurídicas. 2. ed. São Paulo: Saraiva, 2012. p. 257-281.

SZTAJN, Rachel. Autonomia privada e direito de morrer: eutanásia e suicídio assistido. São Paulo: Cultural Paulista, 2002. 